\title{
Correction of tricuspid atresia
}

\author{
Duncan R. Walker, Costos G. Sbokos, and Stuart C. Lennox \\ From the Department of Cardiothoracic Surgery, The Brompton Hospital, London
}

Although Fontan and Baudet in 197 I described a physiological correction procedure for tricuspid atresia, very few successful operations have been reported. Two patients corrected 20 and Io months ago at the Brompton Hospital are presented.

These two patients exhibit many of the problems in the management of tricuspid atresia. The first patient aged 20 had undergone three previous palliative operations, a Blalock-Taussig shunt, a Glenn procedure, and an infundibular resection, and therefore presented a number of operative problems. In contrast the second patient, aged 8, whose condition had deteriorated considerably over the previous year, had had no previous surgical treatment. At operation he was found, in addition, to have a partial atrioventricular canal. Details of the operative procedures and the patients' postoperative course are described. The criteria for selection of patients for the Fontan operation are discussed as are the possible long-term hazards of homograft failure, atrial dysrhythmias, and hepatic dysfunction.

The successful outcome of these two patients suggests that palliative surgery in infancy should allow for this form of correction in later life.

Until recently the surgical management of children with tricuspid atresia was the relief of hypoxaemia by palliative surgery in the form of systemico-pulmonary or cavo-pulmonary anastomoses. These procedures are invaluable, but they result in only partial clinical improvement and can thrombose in time or produce pulmonary hypertension. Fontan and Baudet (197I) developed a physiological correction procedure for this malformation in which the whole of the systemic venous return is carried to the lungs and intracardiac blood mixing is prevented. The conversion of the right atrium into an outlet to the main pulmonary artery is achieved by the use of an aortic homograft conduit. The atrial septal defect is closed and a homograft valve is inserted into the inferior vena cava/right atrial junction. Two patients who have been submitted to this operation are reported here; both survived and are now alive and well 20 and Io months, respectively, after operation.

\section{Case reports}

\section{Case I}

Our first patient underwent operation at the age of 20 years. Cyanosis and a heart murmur had been detected at birth. He was originally thought to have tetralogy of Fallot and had an infundibular resection at age 2. This Received 9 August 1974. procedure partially improved his condition, but within a year he required a further operation in the form of a left Blalock-Taussig anastomosis. At the age of 7 years he had cardiac catheterization with angiocardiography and was recognized to have tricuspid atresia with pulmonary hypoplasia and a small ventricular septal defect. A Glenn procedure was performed at the age of to years. He remained well until 1970 when he was noted to be more cyanosed and had increasing shortness of breath on exertion. Over the next 2 years he gradually deteriorated. On examination he was deeply cyanosed and there was clubbing of the fingers and toes. A loud systolic murmur was heard at the apex radiating along the left edge of the sternum. The blood pressure was I Io/70 $\mathrm{mmHg}$ (14.6/9.3 $\mathrm{kPa}$ ). There was no evidence of cardiac failure. He was polycythaemic with $\mathrm{Hb} \mathrm{I} 9 \mathrm{~g} / \mathrm{dl}$ and PCV 56 per cent. In October 1972 repeat cardiac catheterization and angiocardiography confirmed a type $\mathrm{IB}$ tricuspid atresia (Edwards and Burchell, 1949), with pulmonary arteries of good size. A functioning Glenn anastomosis was noted, but there was no evidence of the left BlalockTaussig shunt.

Operation (Fig. I) was performed on I6 October 1972 through a median sternotomy incision. Massive collaterals were present and the pericardium was closely adherent. The superior vena cava/right pulmonary artery anastomosis was displaced superiorly leaving a long atretic proximal right pulmonary artery behind the aorta. The superior vena cava between the anastomosis and the right atrium was also atretic. The right atrium was large and the main and left pulmonary arteries were 


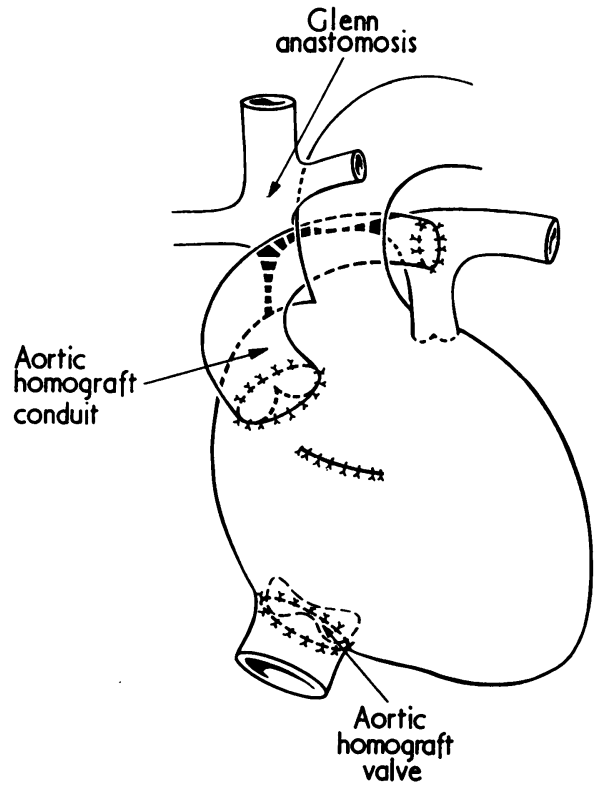

FIG. I Diagrammatic appearance of the heart after insertion of homograft conduit behind the aorta, closure of atrial septal defect (secundum type), and insertion of homograft valve at RA/IVC junction. The previous Glenn procedure is shown with the atretic segments of right pulmonary artery medially and superior vena cava proximally.

of good size with a low pressure (15 mmHg (2.0 $\mathrm{kPa})$ ). A long homograft consisting of an aortic valve and aorta including the arch, was prepared by closing the orifices of the coronary arteries and head vessels. This was then anastomosed to the right atrium, tunnelled behind the aorta, and anastomosed end-to-side to the main pulmonary artery.

Cardiopulmonary bypass was then established by cannulating the right and left innominate and right femoral veins. The arterial return was to the right femoral artery. The right atrium was opened and a free aortic valve homograft was inserted into the right atrial/ inferior vena caval junction. This was held in position by interrupted sutures into the lower margin and continuous sutures to the upper margin. The ostium secundum defect $(4 \times 2 \mathrm{~cm})$ was then closed. After closing the right atrium the patient came off bypass well. The main pulmonary artery was not ligated in this patient. The pressure in the right atrium, superior vena cava, and inferior vena cava was $20 \mathrm{mmHg}(2.7 \mathrm{kPa})$ (mean). Left atrial pressure was $15 \mathrm{mmHg}(2 \mathrm{kPa})$ when the aortic pressure was $100 / 60 \mathrm{mmHg}$ (13.3/8.0 $\mathrm{kPa}$ ). The pressure in the pulmonary artery was $15 / 10 \mathrm{mmHg}(2.0 / 1.3 \mathrm{kPa})$. The chest was closed when haemostasis had been achieved. The initial postoperative course was very smooth. He was pink and was in sinus rhythm at 80 per minute with blood pressure of
$120 / 60 \mathrm{mmHg}(16.0 / 8.0 \mathrm{kPa})$. Ventilation was discontinued 5 hours after his return from theatre. He remained in sinus rhythm and stable with no support apart from continuous plasma infusion. Five days postoperatively aspiration of serosanguineous right pleural effusion was required. Reinvestigation by cardiac catheterization on 8 November showed a small intra-atrial communication. He was discharged from hospital 22 days after operation and has remained well and asymptomatic. His liver is palpable $2 \mathrm{~cm}$ below the right costal margin. The liver function tests are normal. There is no oedema of the lower limbs. Chest $x$-ray shows normal pulmonary vasculature and the $\mathrm{Hb}$ is $15 \mathrm{~g} / \mathrm{dl}$ with a PCV of 45 per cent. The patient was not anticoagulated but has continued to take $0.25 \mathrm{mg}$ digoxin and small doses of diuretics.

\section{Case 2}

Our second patient was an 8-year-old boy in whom cyanosis and a heart murmur had been detected at birth. Cardiac catheterization and angiocardiography had been carried out at age 3 and a diagnosis of tricuspid atresia with pulmonary hypoplasia and a small ventricular septal defect was made. He was followed up at regular intervals and appeared to be progressing well though deeply cyanosed. By June 1973 his exercise tolerance was conspicuously decreased and he complained of severe headaches. Examination showed him to be above the 5oth percentile for height and above the 75th percentile for weight. There was severe cyanosis and clubbing of fingers and toes. A pansystolic murmur was heard at the left sternal edge. There was no evidence of heart failure. His Hb was $19.3 \mathrm{~g} / \mathrm{dl}$, PCV 60 per cent. Repeat cardiac catheterization and angiocardiography showed him to have type IB tricuspid atresia with good sized pulmonary arteries. It was decided to proceed to physiological correction rather than palliative surgery.

Operation (Fig. 2) was performed on 9 July 1973. The chest was opened through a median sternotomy incision. The right atrial appendage was clamped and amputated. An aortic homograft conduit, consisting of ascending aorta, aortic valve, and anterior cusp of the mitral valve (antibiotic sterilized and stored at $-70^{\circ} \mathrm{C}$ ) was inserted between the right atrial appendage and the main pulmonary artery in front of the aorta. Cardiopulmonary bypass was then established using superior vena cava and left femoral vein, with return via the aorta. The right atrium was opened and a typical ostium primum defect was found with a large atrial septal defect and a completely cleft anterior cusp of the mitral valve. The mitral valve was repaired with interrupted sutures and the low atrial septal defect was repaired with a 'dacron' patch. A free aortic homograft valve was then inserted into the inferior vena caval junction with the right atrium. The right atriotomy was closed and the patient came off bypass well. The main pulmonary artery was then ligated using braided ductus silk. The postoperative course was uneventful. He was pink and warm. He did, however, have a fast nodal rhythm, 200 per minute, which gradually slowed with treatment by digoxin over the next 6 


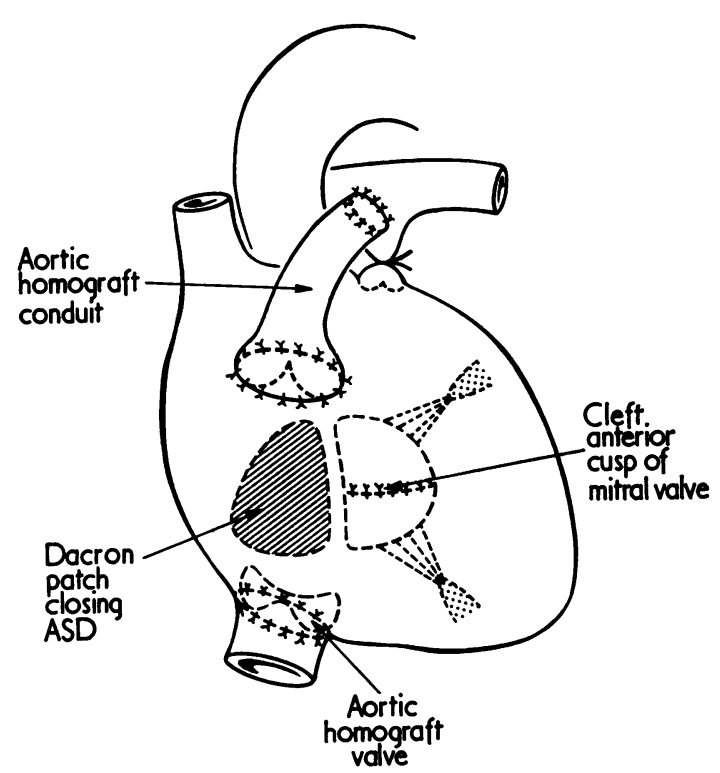

FIG. 2 Case 2. Diagrammatic appearance of the heart after insertion of homograft conduit, closure of atrial septal defect (primum type), and suture of cleft anterior cusp of mitral valve. A free aortic homograft has been inserted at the junction of right atrium and inferior vena cava. The main pulmonary artery has been ligated.

hours. Extubation occurred 6 hours after return from theatre and apart from continuous plasma infusion he required no support. On the $4^{\text {th }}$ postoperative day hepatomegaly, bilateral pleural effusions, and scrotal oedema were noted. Intensive treatment with diuretic and digoxin was started and by the roth postoperative day there was no evidence of fluid retention, apart from slight ankle oedema. The nodal rhythm persisted at a controlled rate of roo per minute. The child was discharged from hospital 28 days after operation, active and well.

The clinical course is satisfactory some ro months postoperatively. He is very active, with a good appetite. There is no evidence of cyanosis even on severe exercise. There is no evidence of venous congestion in the upper half of the body. There is hepatomegaly $3 \mathrm{~cm}$ below the right costal margin, but no oedema of the lower limbs. The chest $x$-ray shows normal vasculature of the lung fields. The liver function tests are normal and his $\mathrm{Hb}$ is $13.7 \mathrm{~g} / \mathrm{dl}$, with a PCV of 42 per cent. A small dose of digoxin is his sole requirement.

\section{Discussion}

These two patients parallel the experience of Stanford et al. (1973), Ross and Somerville (1973), and Fontan and Baudet (1971) in that the operation is feasible and at least initially it gives good results. The first patient, now 20 months since operation, illustrates the common course of patients with tricuspid atresia in that having had three palliative operations he was extremely disabled by the age of 20 and further palliative surgery seemed impossible. The previous operations and the large collaterals made for early difficulties in exposing the heart. The Glenn operation at a young age resulted in the superior vena cava and right pulmonary artery being displaced superiorly. The large aorta dominated the operating field and it was obvious that the conduit could not be placed anteriorly without being compressed when the sternum was closed. It was, however, possible to place it behind the aorta. The proximal part of the right pulmonary artery had atrophied following the Glenn operation. A long segment of ascending aorta and arch was used as the conduit, and was anastomosed to the right atrium and the main pulmonary artery. The superior vena cava was short and surrounded by adhesions and cannulation for bypass was a problem. This was resolved by intubating both innominate veins and the right femoral vein. With the inferior vena cava occluded it was difficult to suture the lower margin of the homograft valve to the inferior vena cava/right atrial junction. However, by placing a large dilator through the valve and into the inferior vena cava which was then snugged around it, it was possible to insert multiple interrupted sutures to the lower margin. Encouraged by the first operation it appeared reasonable to operate on our second patient who was extremely disabled by the age of 7 years. He had had no previous operations. This resulted in a much simpler procedure. It was possible to place the homograft anteriorly without the risk of sternal compression. It was, however, a surprise to find a typical ostium primum defect present. This had to be repaired with a 'dacron' patch and closure of the cleft anterior cusp of the mitral valve. Both patients had a remarkably uneventful postoperative course and required no drug support. As noted by both Fontan and Stanford these patients required almost continuous plasma infusion to maintain cardiac output. Both patients were extubated within 6 hours of their return to the intensive care unit, as it was felt that continuation of positive pressure ventilation would impede central venous return. Our second patient developed a fast nodal rhythm early in the postoperative period with a rate of up to 200 beats per minute; during this tachycardia his cardiac output remained satisfactory. This tends to support Stanford's view that effective atrial contraction is not necessary for the success of this procedure. He based 
his opinion on one patient who had no evidence of atrial contraction on electrocardiogram, but was well six months after operation. Against this, Ross and Somerville (1973) quote their patient who developed an atrial dysrhythmia and had to be readmitted to hospital for treatment. If, however, atrial contraction is unnecessary one wonders about the necessity of having a valve at the inferior vena caval/right atrial junction, and Kreutzer et al. (1973) have recently reported a successful correction of a patient in whom no valve was inserted and there was apparently no angiographic sign of reflux postoperatively. By omitting this valve the operation would be considerably easier and also there would be less risk from late homograft failure. If a continued high venous pressure is necessary in order to perfuse the lungs, it is possible that this may have an adverse effect on the liver and digestive function. Both our patients to date have had normal liver function tests and no evidence of intestinal disturbance.

The main considerations to be taken into account when selecting patients for this procedure appear to be the age and size of the patient, the anatomical type of the lesions, and the possible late hazards of the operation. In this respect one is concerned with the durability of the homografts, the effect of dysrhythmias, and the prolonged effect of increased venous pressure on the liver and digestive tract. In reviewing our experience of 53 patients with tricuspid atresia (in preparation) we have found that they either presented within the first three months of life, usually as an emergency, or did not require help before the age of 3 or 4 years. Our second patient was only 7 years old and weighed $28 \mathrm{~kg}$ and we feel from this experience that the operation would be feasible at least down to a body weight of ro kg. This would have included most of the patients in our series presenting outside the first three months of life. For those patients presenting earlier a number of possibilities exist. First is to perform a palliative operation with a view to correction at a suitable size. If this is done the palliative procedure should be selected with this possibility in mind. Most patients will require an aorto-pulmonary shunt as a pulmonary artery is unlikely to be large enough for a Glenn procedure. Though a Waterston shunt may be technically more satisfactory at this stage, it has some disadvantages. There is a greater tendency to make the shunt too large, leading to pulmonary hypertension, and there is a tendency to kink the right pulmonary artery. In any case it is more difficult to correct satisfactorily before a Fontan procedure. We suggest that a right Blalock-Taussig operation should be performed, using, if necessary, a free graft of the azygos vein. The operative mortality in this group for palliative operation is high and thus a more aggressive approach may be justified. A Fontan procedure as described may be possible, but would require reconstruction with a larger conduit when the child grows. An alternative may be the operation suggested by Kreutzer in which he transposed the main pulmonary artery and valve from the right ventricle to the right atrium. Hopefully this would grow with the child. This operation is anatomically more suited to patients with transposed great vessels.

Both our patients had normally related great vessels. Though the Fontan procedure is possible and often technically easier in dextrotransposition as the right atrium is lying next to the pulmonary artery, in the few patients reported there has been a high mortality. It has been suggested that this is either because of obstruction caused by too small a ventricular septal defect or because of subaortic obstruction (Ross and Somerville, 1973). Fortunately, most patients (in our series, $75 \%$ ) have normally related great vessels. If the operation is performed on the patient with dextrotransposition it may be prudent to examine the ventricular septal defect and the subaortic area.

Much has been written about the fate of homografts. The appearance of calcification with grafts in the venous system is well recognized, but not necessarily important. We used homografts sterilized in antibiotic and stored at $-70^{\circ} \mathrm{C}$. There is growing evidence, however, that fresh homografts may be more durable. The problem of dysrhythmias in the early postoperative period has already been alluded to; however, if recurring later they may cause problems as described by Ross and Somerville, (1973). So far we have found no evidence of hepatic or digestive tract disturbance and the liver function tests have remained normal in both patients.

In conclusion, we feel that it is now justified to advise this operation at least in patients with type I tricuspid atresia who weigh more than $10 \mathrm{~kg}$; for infants presenting as an emergency we suggest that a right Blalock-Taussig shunt should be created as an interim measure.

We thank Dr. R. V. Gibson and Dr. M. C. Joseph for their help and advice and for the pre- and postoperative investigation of the patients.

\section{References}

Edwards, J. E., and Burchell, H. B. (1949). Congenital tricuspid atresia: a classification. Medical Clinics of North America, 33, 1177.

Fontan, F., and Baudet, E. (I97I). Surgical repair of tricuspid atresia. Thorax, 26, 240. 
Kreutzer, G., Galindez, E., Bono, H., De Palma, C., and Laura, J. P. (1973). An operation for the correction of tricuspid atresia. Fournal of Thoracic and Cardiovascular Surgery, 66, 613.

Ross, D. N., and Somerville, Jane (1973). Surgical correction of tricuspid atresia. Lancet, $1,845$.

Stanford, W., Armstrong, R. G., Cline, R. E., and King,
T. D. (1973). Right atrium - pulmonary artery allograft for correction of tricuspid atresia. Fournal of Thoracic and Cardiovascular Surgery, 66, 105.

Requests for reprints to Stuart C. Lennox, F.R.C.S., Department of Cardiothoracic Surgery, Brompton Hospital, Fulham Road, London $\mathrm{SW}_{3} 6 \mathrm{HP}$. 